\title{
Motivos espirituales de la evolución jurídica $y$ meta del progreso jurídico: una visión desde la filosofía del derecho
}

Angelo Anzalone

Universidad de Córdoba, España 


\title{
Motivos espirituales de la evolución jurídica y meta del progreso jurídico: una visión desde la filosofía del derecho"
}

\begin{abstract}
Resumen: ¿cuáles son los motivos de la evolución jurídica? ¿Es más oportuno sostener un progreso jurídico in infinitum o in finitum? Mediante un breve recorrido especulativo, de corte neo-idealista y más concretamente espiritualista, deseamos compartir con el lector algunas posibles respuestas que tienen la finalidad de proclamar y reivindicar la verdadera importancia de los valores que deben presidir todas las manifestaciones jurídicas (pasadas, actuales y futuras): nos referimos a la libertad humana y a las personas entendidas como fundamento de juridicidad.
\end{abstract}

Palabras clave: persona; libertad; derecho; espíritu; idealismo; historia.

\section{Spirituals reasons of legal evolution and goal of legal progress: a view of philosophy of law}

\begin{abstract}
Is it more timely to sustain legal progress in infinitum or in finitum? Trough a brief speculative look, neo-idealist, concretely spiritualistic, we want to share with the reader some possible answers which are intended to proclaim and to assert the real importance of values that must govern every legal manifestation (past, present and future): we are referring to human freedom and person understood as legal foundation.
\end{abstract}

Keywords: person; freedom; law; spirit; idealism; history.

Fecha de recepción: 4 de octubre de 2018

Fecha de aceptación: 16 de enero de 2019

Forma de citar (APA): Anzalone, A. (2019). Motivos espirituales de la evolución jurídica y meta del progreso jurídico: una visión desde la filosofía del derecho. Revista Filosofía UIS, 18(1), doi: http://dx.doi.org/10.18273/revfil.v18n1-2019002

Forma de citar (Harvard): Anzalone, A. (2019). Motivos espirituales de la evolución jurídica y meta del progreso jurídico: una visión desde la filosofía del derecho. Revista Filosofía UIS, 18(1),51-66.

Angelo Anzalone: italiano. Profesor Filosofía del Derecho, Universidad de Córdoba, España. PhD en Derecho con Mención Internacional. Miembro del grupo de investigación SEJ-050 "Comunicación, derecho y técnicas o procedimientos de enlace sistémico".

Correo electrónico: ji2anana@uco.es

ORCID:https://orcid.org/0000-0002-1763-5737

* Artículo de investigación científica. 


\section{Motivos espirituales de la evolución jurídica y meta del progreso jurídico: una visión desde la filosofía del derecho}

\section{Anterioridad, posterioridad o intrinsicidad de la relación Ser Humano-Derecho}

Sostener una concepción de derecho entendido como un momento no meramente abstracto de la vida, sino práctico y en concreto desarrollo, real en sus manifestaciones económicas o morales, fruto de la relación humana y alejado de una idea platónica que lo separa de la vida concreta, requiere demostraciones y reflexiones de carácter histórico. Cuál sea el origen del derecho o cuál sea la relación entre ser humano y derecho, son cuestiones, íntimamente relacionadas entre sí, que podríamos intentar resolver Ilamando en causa elementos de naturalezas muy diferentes: sociológicos, etnológicos, prehistóricos, arqueológicos, entre otros. En cambio, una aproximación ciertamente inoportuna, o por lo menos reductiva, consistiría en prescindir de modelos especulativos, limitándonos a observar que el derecho surge de los meros hechos, considerando tal origen como contingente y no real y necesariamente invocado por la esencia de la naturaleza humana ${ }^{1}$.

Los posibles planteamientos acerca de la relación ser humano-derecho son varios. Es posible considerar que el derecho sea anterior al ser humano, admitiendo así la existencia de principios y reflejos de leyes naturales que actúan entre los animales y también entre los seres humanos². En segundo lugar, puede considerarse al derecho como posterior al ser humano, sosteniendo, de este modo, que la humanidad habría tenido la necesidad de organizarse social y

\footnotetext{
${ }^{1}$ Así lo advierte Giorgio Del Vecchio, uno de los principales representantes del neokantismo italiano (Del Vecchio, 1905, pp. 40ss.). En estos términos se expresa también Battaglia (1951, p. 137). Es preciso señalar que de los orígenes y del devenir histórico del derecho hemos tratado en un estudio monográfico más amplio, que nos ha servido como punto de partida para algunas partes del presente manuscrito; nos referimos a Anzalone (2013, pp. 100-113).

${ }^{2}$ En caso de adoptar dicha postura, tendríamos que admitir la dependencia o la identificación de las leyes humanas con las físicas, cosa que no procede ya que, si éstas representan un orden inviolable de conformidad al mundo de la naturaleza, aquéllas presuponen la libertad e implican una clasificación entre lo justo y lo injusto (Battaglia, 1951, p. 138, quien nos presenta la visión global de Fragapane, 1896).
} 
políticamente para salir de un estado de anarquía y de lucha ${ }^{3}$. En último lugar, podemos sostener que el derecho sea intrínseco al ser humano, manteniendo pues la inexistencia del ser humano aislado, siendo la organización social —según la enseñanza aristotélica- su condición originaria.

Efectivamente, ser hombre equivale a vivir en una sociedad, ya que los seres humanos buscan la comunicación intersubjetiva para vivir en común, organizarse y asegurarse unas mínimas condiciones de vida mediane reglas que permitan una mejor convivencia y que, por tanto, dan lugar a un teijdo jurídico. Esto significa que, si la sociedad es algo intrínseco al ser humano, también debe serlo el derecho en cuanto aparato instrumental apto para asegurar las condiciones de coexistencia. Aceptar este último posicionamiento doctrinal, por tanto, equivale a rechazar la existencia de una época en la que el ser humano no haya conocido cierto orden jurídico, por tosco e inconsciente que éste fuera (Fragapane, 1896, pp. 54-64).

Ahora bien, ¿cuáles son los elementos y los motivos de la naturaleza humana que fundamentan la existencia del derecho desde sus comienzos más remotos? Este tipo de operación requiere un esfuerzo especulativo, consistente en la búsqueda y en la comprensión de los motivos del espíritu humano que actuaron ayer, que lo hacen hoy y que, seguramente, lo harán mañana. En la mencionada intrinsicidad (ser humano-derecho) hay que detectar algo que caracteriza nuestra experiencia jurídica y que sea capaz de definirla como típica con respecto a las posibles experiencias jurídicas primitivas o futuras. En este sentido, consideramos que un elemento indudablemente importante para el origen del derecho, en todo tiempo y lugar, es la acción. Queremos decir que para la existencia de elementos jurídicos no son suficientes los propósitos estériles, ya que siempre son necesarios unos objetivos alcanzables solo y exclusivamente mediante la actuación del querer. La acción, fruto del querer en sus manifestaciones prácticas y concretas, tiene como destinatarios otras personas, otros seres humanos y, por tanto, entra en conexión con otras acciones. De "acción comunicativa", por ejemplo, nos habla Habermas cuando apela al necesario entendimiento que la razón comunicativa produce, en ciertas condiciones, en los participantes de una comunicación orientada hacia ciertos fines de la vida (entre ellos, los que alcanzan relevancia jurídica) ${ }^{4}$.

\footnotetext{
${ }^{3}$ Recordamos que Hobbes y Spinoza, entre otros, se caracterizan por haber defendido, aunque sea con rasgos diferentes, tales posturas.

4 "El término «entendimiento» tiene el significado mínimo de que (a lo menos) dos sujetos lingüística e interactivamente competentes entienden idénticamente una expresión lingüística...Y para entender lo que un hablante quiere decir...el oyente tiene que conocer las condiciones bajo las que puede ser aceptado... Si el oyente, en efecto, acepta la oferta que un acto de habla entraña se produce entre (a lo menos) dos sujetos capaces de lenguaje y acción un acuerdo. Pero éste no solamente se basa en el reconocimiento intersubjetivo de una única pretensión de validez temáticamente subrayada, sino que tal consenso se busca simultáneamente en tres planos. Estos son fáciles de identificar intuitivamente, si se considera que la
} 
De aquí la necesidad de una delimitación recíproca entre posibles acciones en contraste $y$, por tanto, el origen del derecho bajo la forma de disciplina y delimitación de conductas con el objetivo de instaurar un orden de posibilidades y, al mismo tiempo, de imposibilidades. Un proceso que implicará, necesariamente, el reconocimiento de posiciones recíprocas (Battaglia, 1951, p. 141). La bilateralidad del fenómeno jurídico, es decir ese reconocimiento y delimitación entre seres humanos, presupone que desde el primer encuentro entre dos hombres encontramos los gérmenes de la espontaneidad humana, generándose así tres fases consecuentes y fundamentales que dan origen a toda forma de juridicidad. Como ya pudimos comprobar (Anzalone, 2016, p. 32), nos referimos a la afirmación de nuestra personalidad, al reconocimiento de la del otro y al establecimiento de una coordinación mutua entre conductas. Del primer encuentro inter-humano, por tanto, derivan todas las consecuencias que el derecho conoce en su historia: costumbres, leyes, instituciones, órdenes, sistemas jurídicos, etcétera (Battaglia, 1951, p. 143).

Estas afirmaciones, evidentemente, contrastan con aquellas ideas según las cuales la idea de derecho solo tiene lugar en la conciencia humana en cuanto el ser humano, adquiriendo el sentido de su propia fuerza muscular, experimentando y temiendo el peligro del mal, prefiere optar por una idea de delimitación recíproca, poniendo normas comunes ${ }^{5}$.

razón por la que en la acción comunicativa un hablante escoge una expresión lingüística inteligible es para entenderse con un oyente sobre algo y a la vez darse a entender a sí mismo. La intención comunicativa del hablante comprende, pues, a) el realizar un acto de habla que sea correcto en relación con el contexto normativo dado, para poder con ello establecer una relación interpersonal con el oyente, que pueda considerarse legítima; b) el hacer un enunciado verdadero (o presuposiciones de existencia ajustadas a la realidad) para que el oyente pueda asumir y compartir el saber del hablante; y c) el expresar verazmente opiniones, intenciones, sentimientos, deseos, etc., para que el oyente pueda fiarse de lo que oye. Pues bien, el que todo consenso normativamente alcanzado genere una comunidad intersubjetiva que cubre tres planos distintos: el de un acuerdo normativo, el de un saber preposicional compartido, y el de una mutua confianza en la sinceridad subjetiva de cada uno, es algo que a su vez puede explicarse recurriendo a las funciones del entendimiento lingüístico. Como medio (Medium) en que se produce el entendimiento (Verständigung), los actos de habla sirven a) al establecimiento y renovación de relaciones interpersonales, en las que el hablante hace referencia a algo perteneciente al mundo de las ordenaciones legítimas; $b$ ) a la exposición o a la presuposición de estados y sucesos, en los que el hablante hace referencia al mundo de estados de cosas existentes y c) a la expresión de vivencias, esto es, a la presentación que el sujeto hace de sí mismo, en que el hablante hace referencia a algo perteneciente a su mundo subjetivo al que él tiene un acceso privilegiado. El acuerdo alcanzado comunicativamente se mide justo por estas tres pretensiones de validez susceptibles de crítica, ya que los actores, al entenderse entre ellos sobre algo y darse así a entender a sí mismos, no pueden menos de insertar sus actos de habla precisamente en estas tres relaciones con el mundo y reclamar para ellos validez bajo cada uno de estos aspectos" (Habermas, 1998, pp. 393-394).

${ }^{5}$ No pretendemos negar que la comparación de las fuerzas, en el hombre primitivo, haya podido producir la exigencia de delimitaciones reciprocas. Solo queremos sostener que este factor no puede ser ciertamente el único fundamento del surgir del derecho. En sentido opuesto, por ejemplo, Carle sostiene que el derecho ha surgido de la idea de delimitación de contrastes entre inteligencias o habilidades, en vez de solamente entre fuerza física (Carle, 1875, pp. 27ss.). 


\section{La originaria pertenencia impersonal del individuo al grupo social}

Una gran cantidad de estudiosos coinciden en que el prototipo de familia romana constituye la primera y real institución social y política (Cerami-CorbinoMetro-Purpura, 2001, pp. 3ss.). Otras investigaciones, en cambio, sostienen que la primera forma organizada de convivencia fue la horda. En efecto, ha sido demostrado que en esta agrupación es posible encontrar el comienzo de la disciplina propia de una familia, más específicamente de la gens, ya que, movida por el deseo de alcanzar ciertas condiciones de vida en un determinado territorio, comenzó a reconocer vínculos duraderos de descendencia. La fase gentilicia ha sido de la más duraderas en la historia de la humanidad, de la cual derivan inmediatamente las tribus (agrupaciones de diferentes gens) que, uniéndose, dan lugar a las primeras ciudades primitivas, siendo Roma y Grecia los más ilustres ejemplos (Battaglia, 1951, pp. 147-150).

Las fuerzas que aseguran la organización de los grupos que acabamos de mencionar (jefes, consejo de ancianos, etc.) actúan para asentar una fuerte cohesión, pero en detrimento de la personalidad propia del individuo. Este nace en el grupo, desarrolla su propia vida en él, muere en él. No se concibe una vida autónoma, pudiéndose hablar a tal propósito de una pertenencia impersonal al grupo. Las consecuencias son evidentes, ya que el grupo se sujeta mediante una sólida disciplina consuetudinaria, aunque no del todo detallada desde el punto de vista jurídico, moral o religioso, características que aparecerán más tarde de manera más nítida y, sobre todo, separadas entre ellas. Se trata, por tanto, de una costumbre primitiva que se caracteriza por abarcar la totalidad de comportamientos humanos ya que obliga a los hombres en todos los detalles de sus propios actos. Una costumbre particular y conservadora, que tiene el propósito de regir la vida entera del ser humano en cuanto idónea para mantener la solidaridad mecánica del grupo ${ }^{6}$.

También es posible recordar la existencia de una época anterior que, lejos de ser considerada como de libertad sin leyes, debería calificarse como de tiranía del instinto. Queremos decir que si el instinto, por una parte, implica una acción determinada pero inconsciente (parecida a la que realiza un animal), la costumbre, por su parte, está constituida por una serie de normas cuya obligatoriedad supone un libre ejercicio de responsabilidad por parte del sujeto. Por tanto, si la costumbre llega y aparece cuando termina el auge del instinto, el hombre, desde cuando es hombre, es decir, desde cuando vive en agrupaciones sociales, nunca ha vivido

\footnotetext{
${ }^{6}$ Es una costumbre que se presenta con un carácter negativo, bajo la forma de la prohibición y en un sistema de tabú. La costumbre se convierte en tabú, convirtiendo en sagrados unos actos que no hay que realizar y, en todo caso, esto demuestra que el hombre siempre se ha dotado de normas de convivencias básicas (Battaglia, 1951, pp. 150-152).
} 
sin reglas (Maine, 1874, pp. 47, 211 y 345). La pertenencia impersonal al grupo y las dificultades para llevar a cabo una vida autónoma — en el sentido de vida independiente de las dinámicas grupales - tienen, entre otras consecuencias, la exclusión de la tutela del grupo como la sanción más severa para el transgresor de un tabú. Tal como era sagrado el grupo, lo era la costumbre, y las instituciones crueles que representaron tales sanciones fueron, por ejemplo, en Roma, la aquae et ignis interdictio (literalmente privación del agua y del fuego) o, en los germanos, la proclamación del culpable vogelfrei (prisionero de los pájaros, en el sentido de que su cadáver habría sido consumido por ellos). Se habla, por tanto, de reacción solidaria a la violación de una costumbre ${ }^{7}$.

Múltiples han sido las fases y formas intermedias que sancionaron el paso de las sociedades mecánicas a modelos sociales menos opresores de la personalidad del individuo ${ }^{8}$, y la historia romana es testigo del modo en que el derecho proviene paulatinamente de la costumbre. En este sentido, no se asiste a una creación ex novo y ya hemos dicho que la costumbre primitiva, intrínseca al ser humano en sus primeras manifestaciones sociales, abarca aspectos morales, religiosos y ceremoniosos no netamente definidos y separados entre ellos. Habrá que esperar siglos para que la juridicidad consiga aparecer como diferenciada de otros órdenes afines, adquiriendo así caracteres y funciones más específicos. La distinción entre costumbre primitiva y derecho, por tanto, no es tanto de forma como de contenido, ya que esa separación se consume una vez madurada una auténtica concepción de juridicidad como libertad y no como mera prohibición o coacción. El derecho es libertad en cuanto implica un orden donde las esferas de posibilidades e imposibilidades aseguran a los sujetos unas zonas de acción garantizadas y tuteladas. En este sentido el derecho garantiza la libertad.

\section{Motivos espirituales de la evolución jurídica}

Podríamos afirmar que en la evolución jurídica participan factores materiales, dados por el conjunto de condiciones físicas capaces de promover la configuración y transformación de un sistema jurídico determinado (por ejemplo, la posición geográfica de un territorio), y espirituales, constituidos por complejos motivos interiores que mueven al ser humano hacia el establecimiento de una coordinación y delimitación inter-subjetiva. En este sentido, Giambattista Vico quiso trasmitirnos la idea de un derecho íntimamente y necesariamente relacionado con las circunstancias sociales y los motivos de la sociedad humana, una concepción que pretende fomentar la participación del devenir histórico en el devenir jurídico,

${ }^{7}$ En este caso volvemos a utilizar las observaciones de Battaglia (1951, pp. 154-155), quien a su vez resume las consideraciones que sobre estos aspectos ha formulado Maine (1998 y 1883).

${ }^{8}$ Nos referimos a determinadas costumbres "salvajes" que empiezan a decaer en el tiempo; al surgir de instituciones como la posesión y la propiedad individual; o a una evolución penal en la que se manifiestan las primeras formas de institución jurídica de la pena acompañada por un mínimo criterio de proporcionalidad (Battaglia, 1951, pp. 156 ss.). 
implicando una conexión esencial entre las condiciones socio-ambientales y los hechos jurídicos, admitiendo una cierta regularidad y continuidad de algunos caracteres dominantes sin llegar a someter los eventuales cambios y progresos jurídicos a la fatalidad de principios eternos a priori ${ }^{9}$.

Es en el ámbito del neo-idealismo italiano, de corte espiritualista, donde se sostiene que la vida entera emana del pensamiento, una posición especulativa que no propone la idea de pensamiento opuesto a la voluntad, sino de pensamiento (astracto y potencialmente concreto) que pone la voluntad y que se pone como voluntad (concreta); en este sentido, el pensamiento encuentra sus formas concretas en las determinaciones prácticas que la historia conoce, siendo no solo forma abstracta sino contenido práctico real (Anzalone-Sánchez Hidalgo, 2016, p. 14). Las afirmaciones hegelianas según las cuales todo lo racional es real y lo real es racional, no se entienden — según el neo-idealismo italiano- en el sentido de que todo lo que existe en la historia sea racional, sino en el sentido de que lo que aparece en la historia lleva el sello de la racionalidad, en cuanto el pensamiento presenta siempre la exigencia de traducirse en realidad histórica, otorgándole a ésta un sentido racional (Battaglia, 1951, pp. 186-187).

Felice Battaglia nos ofrece una clave de lectura, sosteniendo que la razón, según Hegel, no es la lógica abstracta de los viejos dogmáticos, ni el orden de los conocimientos, entendido como un proceso abstracto que se mueve en sus mismos términos sin posibilidad de salida. La razón, en Hegel, según la interpretación de Battaglia, rompe los términos del abstracto, ya que reúne en si todas las determinaciones de la realidad, mediante un proceso que implica una profunda unidad generadora de realidad impregnada de un sentido ideal y que, al mismo tiempo, exige un proceso de manifestación práctica y concreta. La mencionada unidad, entre verdad y hecho, entre racional y real, entre filosofía e historia, requiere un principio unitario que los idealistas denominan de modo diferente. Aunque aluden al mismo valor especulativo, según Vico se trata de la mente humana, según Hegel de la idea, según Croce y Gentile del espíritu (Anzalone-Sánchez Hidalgo, 2016, p. 14).

La categoría del espíritu habría que entenderla como una unidad trascendental, capaz de plasmar en lo concreto las necesidades históricas del pensamiento y del ser. Es una categoría dialéctica que se desarrolla y adquiere sentido al calificar el orden histórico y fenoménico. Por tanto, ordo idearum y ordo rerum intentarán compenetrarse recíprocamente y, en el ámbito jurídico, esto quiere decir que la historia desarrolla una idea de derecho que convierte en reales y concretas las formas absolutas que la filosofía desarrolla y propone en el campo de lo trascendente. Esto equivale a sostener una idea de derecho dinámico que implica una constante traducción, en la realidad, de los valores de los que es portadora la

${ }^{9}$ Sobre las posturas de Vico, véase el analisis realizado por Croce, 1980. 
historia, ya que ni la juridicidad podrá ser total y definitiva ni el devenir histórico podrá ser siempre capaz de celebrar el sello definitivo de la racionalidad. Admitir o concluir lo contrario significaría perder el verdadero sentido espiritual de libertad (Battaglia, 1951, pp. 187-189).

El derecho, pues, y así lo hemos mantenido en otras ocasiones (Anzalone, 2016, p. 32), atribuye a la realidad el auténtico sentido de libertad humana, revelando las heterogéneas exigencias sociales y traduciéndolas en sistemas sociales y jurídicos concretos mediante una cooperación y comunicación social cada vez más urgente y necesaria. Así, y solo así, sociedad y juridicidad se corresponderán desde los puntos de vista trascendental e histórico, ya que se trata de un verdadero proceso de interacción comunicativa que —siguiendo la más reciente postura de Habermas - situaría la deliberación colectiva como fuente de legitimidad de lo jurídico y, al mismo tiempo, como factor de corrección de sus contenidos $^{10}$.

\section{Meta del progreso jurídico: entre abstracción y concreción}

En las primeras páginas de este trabajo, insinuamos que afirmar la propia personalidad, reconocer la del otro y limitar (regular) los respectivos espacios de actuación son elementos constantes y esenciales siempre presentes en el devenir histórico-jurídico ${ }^{11}$. Dichas constantes (según Del Vecchio, 1945, pp. 7ss.) representan la auténtica juridicidad, pues principalmente del reconocimiento de los demás seres humanos y del respeto reciproco de las respectivas esferas de libertad deriva la experiencia jurídica. Battaglia nos recuerda que, en términos parecidos, Giambattista Vico llamó la atención de los estudiosos tras haberse referido a la existencia de unidades sustanciales de la humanidad. En este sentido, el ilustre filósofo napolitano afirmó la exigencia de un derecho universal y eterno, uniforme para todas las naciones, apto para plasmar todas las necesidades humanas, sobre las que encuentra constantemente sus propios orígenes y los motivos de su progreso (Battaglia, 1951, pp. 192-194). Llamativas, en este orden de ideas, las

\footnotetext{
${ }^{10}$ En este sentido, cabe recordar que el reconocido filósofo y sociólogo alemán observa que la unidad del colectivo puede mantenerse y sostenerse solo como "unidad de una comunidad de comunicación", es decir a través de un consenso comunicativamente alcanzable en el seno de la opinión pública política (Habermas, 1992, p. 118). Y es que los rasgos fundamentales del lenguaje, según Habermas, permiten comprender que las instituciones dependen también de los efectos directamente originados por un consenso formado lingüísticamente. La integración en sociedad, por tanto, no solamente se lleva a cabo mediante la institucionalización de valores sino también mediante el reconocimiento intersubjetivo de "las pretensiones de validez que los actos de habla comportan", puesto que "las acciones comunicativas permanecen insertas en los contextos normativos existentes; pero, con sus actos de habla, el hablante puede referirse explícitamente a ellos y adoptar frente a ellos posturas diversas". Por estas razones, y debido a la fuerza que adquieren los actos de habla, gran consideración merece el conjunto de notables consecuencias que dichos actos pueden producir incluso para la validez (además que para la aplicación) de las normas (Habermas, 1992, p. 128).

11 Todo ello como consecuencia de la necesaria bilateralidad del fenómeno jurídico. Un estudio más detenido en Anzalone (2016, pp. 31-32).
} 
palabras que Giorgio Del Vecchio pronunció en el III Congresso internazionale di Diritto comparato celebrado en Londres, en 1950, con un discurso titulado "L'unità dello spirito come base della comparazione giuridica". Según Del Vecchio, en efecto,

[...] existen tendencias uniformes en el desarrollo de los sistemas propios de los distintos pueblos, donde cada uno de ellos recorre sucesivamente, en general, las mismas fases. Eso no quiere decir que falten, en el inmenso cuadro de la vida histórica del derecho, características singulares e incluso desviaciones, transgresiones y anomalías; pero esto no puede impedirnos el reconocimiento de la tendencia general del desarrollo jurídico; y tanto es así que la misma historia nos demuestra que aquellas eventuales desviaciones e involuciones tienen un único destino, o sea, antes o después, caerán, así como las enfermedades del organismo humano nunca pueden ser eternas y deben, de algún modo, resolverse, en la vida o en la muerte; con la diferencia que la muerte de los pueblos es un fenómeno bastante raro (Del Vecchio, 1950, pp. 431-434) ${ }^{12}$.

El escenario de nuestro tiempo es realmente complicado. La individualidad humana es cada vez más rica y compleja, pero eso no debería ser motivo suficiente para abandonar la idea de una necesaria y sólida cohesión en sociedad, en el sentido de que el proceso histórico no se caracteriza por un individualismo atomístico, tratándose, en cambio, del devenir de una sociedad que debería ser menos mecánica y más espiritual (menos apática y más dinámica). La sociedad debe participar con mayor presencia y visibilidad en la elaboración del derecho, creando órganos e instituciones para luego orientarlos. Vico tenía razón al afirmar que en el género humano fueron depositados los gérmenes eternos de la justicia y que la compleja espiritualidad humana se desarrolla, cambia, evoluciona y progresa, siempre movida por esa sed de justicia.

Creemos que hablar de progreso jurídico no es utópico. Es posible argumentar una idea de progreso in infinitum o in finitum. Es posible llegar a conclusiones negativas o positivas. En realidad, y en lugar de buscar y crear una meta temporal del derecho, nos parece más adecuado sostener que el derecho, en su evolución, se mejora y perfecciona con una constante superación que no tiene fin, pero siempre inspirado por un valor último que es la libertad humana. No nos referimos a la libertad de arbitrio sino de autonomía, auto-creación y conocimiento, ya sea en el ámbito moral o jurídico. El derecho es libertad, pero no una mera coexistencia de libertades externas (al puro estilo kantiano) sino libertad en el orden social y libertad real en las instituciones que constituyen el entramado de la vida práctica. De este modo, es posible mantener esa idea de derecho como realidad en la libertad, y esa concepción de derecho futuro como realización de la libertad que

\footnotetext{
${ }^{12}$ La traducción es propia.
} 
es, en el fondo, esencia de la humanidad ${ }^{13}$. Recientemente ha sido observado que los derechos orientados a la libertad son una exigencia permanente, ya que la voluntad que se pretende proteger mediante ellos es permanente, y así sería posible mantener una concepción de derecho ligada a la idea de progreso del individuo y de la sociedad (Zagrebelsky, 2011, p. 86).

En el seno del neo-idealismo italiano, la libertad ha sido entendida como la espiritualidad misma del ser humano, su actividad, su realidad. En esta concepción, el espíritu es capaz de comprender la esencia de la realidad exterior y la propone en términos prácticos y concretos, no siendo pues una entidad abstracta separada de la realidad. Esa espiritualidad, por tanto, sería la esencia misma del ser humano y éste la posee en su calidad de hombre. Por esta razón, la libertad no se puede conceder ya que al ser humano no se le puede conceder algo que ya le pertenece de por sí. Por las mismas razones, tampoco se le podrá privar de ella. En este sentido, los opresores de la libertad han podido apagar seres humanos, han prohibido acciones, han obligado a callar o a mentir, pero no han podido quitar a la humanidad su libertad, es decir, su tejido vital (Croce, 1943, pp. 276-277). Si deseamos invocar el término libertad, por tanto, tendremos que hacerlo con la única y sola posible referencia al deber moral de favorecer y promover la vida de la humanidad, poniendo en la esfera negativa cualquier acción que pueda menospreciarla.

La libertad, así concebida, coincide con un principio de moralidad, ya que contiene, en sí, todo tipo de deber moral y es todo lo que moralmente se hace y se debe hacer, encontrando su fuerza en la vida de la humanidad. Benedetto Croce no acepta que la justicia pueda entenderse como un factor de corrección (positivo o negativo) de la libertad, ya que este último es un concepto espiritual y real que vive siempre y en todos los casos. Además, la justicia ha sido entendida e interpretada según los contextos de referencia, no siendo, por tanto, capaz de acompañar a una categoría espiritual (libertad) que muestra su moralidad humana en todo tiempo y lugar. El ilustre pensador italiano se refiere, fundamentalmente, a cuatro sentidos del término justicia: "la idea de bien moral o del hombre justo; la concepción asociada al derecho o a lo justo legal; la justicia como virtud; la justicia como igualdad...Por esta razón, aunque sea inevitable que, de un modo u otro, a la idea de libertad acabe por aparejarse o sobreponerse la de justicia [...]" (Anzalone, 2018, pp. 181-183) $)^{14}$, el autor sostiene que deben separarse las esferas

\footnotetext{
${ }^{3}$ Un modo de aproximarse a la cuestión al puro estilo idealista, ya que esta corriente ubica el espíritu en el centro de la comprensión del mundo, siendo, el espíritu, libertad. En este sentido resulta interesante la lectura que de la dialéctica hegeliana realiza Giovanni Gentile (1913, pp. 231-241).

${ }^{14}$ De los diversos sentidos que puede adquirir el termino Justicia y de su peligrosa identificación con la idea de Libertad, también hemos tratado en una ponencia presentada con ocasión del Congreso Internacional: "El debate actual sobre las teorías de la Justicia" (Pamplona, 1 y 2 de junio de 2017). El resumen de dicha intervención se encuentra disponible en https://www.unav.edu/ documents/29020/12981524/Ponencia+Anzalone.pdf (Recuperado 8 de octubre de 2018).
} 
de actuación de ambos principios. Por todos los motivos expuestos, y desde el punto de vista doctrinal y filosófico, según Croce (1943, pp. 282-284) resulta casi ofensivo igualar los dos conceptos, las dos ideas, los dos valores, ya que equivale a intentar dormir un delicado problema moral ${ }^{15}$.

Nosotros creemos que ambos valores pueden ciertamente colaborar, promoviendo un ethos jurídico donde encuentren reconocimiento sea las pretensiones jurídicas orientadas a la libertad que aquellas orientadas a la justicia. Y esto lo mantenemos a pesar de que la creación del derecho legislativo representa el resultado de un proceso político y plural a veces marcado por el rasgo de la ocasionalidad (Zagrebelsky, 2011, p. 37) y de la oportunidad. No se deberían crear situaciones en las que parece ser inevitable elegir entre una vida colectiva ordenada hacia la libertad o una vida colectiva orientada hacia la justicia; para conseguirlo solo nos queda la posibilidad de legitimar una tensión dialéctica entre las diversas concepciones de justicia, sabiéndolas conciliar en los diversos momentos históricos-concretos, sin dejar paso al argumento feroz que transforma la libertad en un principio absoluto (95). Se trata, pues, de una adecuada ponderación entre el reconocimiento de derechos individuales y la imposición de deberes que encarnan igualmente ciertas ideas objetivas de justicia.

\section{La persona como fundamento de la juridicidad. Reflexiones finales}

Mediante la organización jurídica en sociedad, en un proceso no pacífico, ya que lo irracional puede siempre tomar protagonismo, el derecho asume motivos morales y los lleva al plano histórico, manifestándose como costumbre, madurando con la jurisprudencia y perfeccionándose en la legislación. En este esquema de esencial vida jurídica, los seres humanos se descubren en el derecho como

\footnotetext{
15 "La libertad y la autonomía son siempre una faceta necesaria de nuestros actos; si ellos carecieran de estas cualidades no serían actos adecuados al hombre. Pero una libertad sin bienes a los que tender no sería propiamente libertad, sino, a lo sumo, lo que los teólogos bajomedievales llamaron el «arbitrium merae indifferentiae». Y entonces no somos libres, sino que quedamos a la merced de la contingencia: la libertad no se compadece con la falta de motivos para la acción. La praxis del hombre, que es su meta, proporciona una cierta objetividad a lo que perseguimos, aunque no siempre conozcamos los medios para alcanzarlo" (Cfr. Carpintero Benítez, 1966, p. 51). Retomando las categorías aristotélicas, podemos recordar las diferencias que median entre el significado de libertad natural y el significado de libertad social; en efecto, "podemos hablar de una denominada «libertad natural» que comprende la capacidad que el individuo puede tener para sustraerse al Orden Cósmico, es decir, al Destino o a la Naturaleza....Esta acepción de libertad encuentra su fundamento en el juicio y la razón humana; solo es libre el hombre en cuanto es ser racional y está dispuesto a actuar como tal, es decir, en cuanto puede entender, y por ello eludir o al menos desafiar, las «leyes» de la naturaleza...En otro sentido, entiéndase en la medida en que el hombre se manifiesta como un ser que convive con sus congéneres formando sociedades políticas, se puede hablar de la «libertad social», que sería aquella que faculta al individuo para hacer lo que su autonomía le dicte dentro de los límites que la vida social impone, límites entre los que se cuenta, claro está, el Derecho" (Cfr. Medina Morales, 1955, pp. 131-132).
} 
personas (Battaglia, 1977, pp. 28-31), ya que el respeto de la persona humana, de sus necesidades, de sus fines y de sus sociedades representa la base del todo ${ }^{16}$. "Derecho natural" lo enunciaba Antonio Rosmini, quien llegó a afirmar que con tal definición hay que entender el derecho de la persona, capaz de satisfacer en la justicia las razones de la sociedad y de la política rectamente entendidas (Battaglia, 1977, p. 39).

Se trata de una solución —la rosminiana — que desea identificar al ser humano con el "fundamento del derecho, valor último para todo derecho positivo. Ese ser humano es la persona entendida desde un punto de vista ontológico, o sea en su intrínseco valor y sustancia" (Anzalone, 2016, p. 28). Desde la persona nace el derecho y, tras su paso por los meandros éticos y religiosos, en la persona concluye la juridicidad. El fundamento de la juridicidad es dado por la persona en cuanto el derecho es una actividad subjetiva que se concreta en una actividad que desea ser útil, cómo resultado del ejercicio de una voluntad libre ${ }^{17}$. Es aquí donde la estructura eudemonológica y relacional del derecho resulta ser fundamental para el respeto de la persona humana en sociedad, así como de sus fines y necesidades.

Desde un punto de vista práctico, esto comporta la búsqueda de una justa articulación entre los planos personales de la vida y la inderogabilidad de algunos valores fundamentales, ya que la búsqueda de utilidades — aunque reconocida y tutelada por el derecho- no puede justificar cualquier tipo de actividad que acabe por poner en peligro las instancias éticas de la vida humana. En efecto, los principios objetivos de justicia deberían servir para obligar a la voluntad deseosa de actuar —individual o colectiva - a confrontarse, moderarse y así aceptar que con ella existen otras fuerzas constitutivas de la juridicidad (Zagrebelsky, 2011, p. 106). Debería perseguirse, pues, una adecuada ponderación entre los derechos entendidos como instrumentos para conseguir utilidades y como conjunto de garantías del orden jurídico desde el punto de vista ético. En otros términos, esto equivale a orientar éticamente los problemas jurídicos para que la comunidad política sea capaz de perseguir el bien común. Una búsqueda de equilibrios realmente compleja, somos conscientes de ello. Y es por esto que deberíamos aprender del error de Hegel, quien sostuvo la necesaria existencia de otros sujetos de la historia al lado de los individuos, que serían los individuos cósmicohistóricos, es decir los Estados; o del error de Marx, quien llegó a considerar la sociedad como único, exclusivo y absoluto protagonista de devenir histórico ${ }^{18}$.

\footnotetext{
${ }^{16}$ Del derecho natural en óptica rosminiana hemos tratado en Anzalone (2016, pp. 27-29).

${ }^{17}$ El concepto de persona entendido como representación del individuo y, a su vez, como representación de la libertad, independencia y autonomía en el ámbito moral y en el ámbito jurídico, ha sido un logro kantiano. Así nos lo recuerda Carpintero Benítez (1987, pp. 498-499).

${ }^{8}$ Battaglia también considera que "Noi pensiamo e confermiamo solo soggetto essere I'uomo, portatore dei valori e nei valori procedente, la società non essendo che un complesso di condizioni, che esso pone e come pone risolve" (Cfr. Battaglia, 1960, pp. 43-44).
} 
Mas bien deberíamos reivindicar que el ser humano, como persona, es la conciencia operativa de una exigencia unitaria, comprensiva y suprema, en cuanto eje temático en las jerarquías entre razón y naturaleza. El ser humano-persona es el auténtico protagonista del devenir histórico y no puede ser considerado como un mero actor secundario de la historia o "un mero ejecutor de un diseño. La lógica de la libertad — a la que hemos aludido anteriormente- requiere un firme carácter histórico de los valores, no en cuanto valores de la Historia sino en cuanto valores en la Historia (Anzalone-Sánchez Hidalgo, 2016, p. 15).

Las tres edades viquianas avanzan al lado de una historia que Vico define ideal, eterna y extratemporal, una historia compatible con el curso terrenal de las cosas. En dicha eternidad y extratemporalidad es necesario encontrar el hilo conductor de todo tiempo y lugar: el valor y la condición de la persona en el conjunto de sus manifestaciones sociales, políticas, culturales, económicas o éticas. Solamente así podremos hablar del fenómeno jurídico capaz de metabolizar los objetivos éticos fundamentales de los distintos tejidos comunitarios que se suceden en el tiempo $^{19}$.

\section{Referencias}

Anzalone, A. (2013). Lo abstracto y lo concreto en la Teoría del Derecho de Battaglia. Felice Battaglia y el dilema entre Croce y Gentile. Barcelona: Atelier.

Anzalone, A. (2015). Interferencias entre política y comunidad deportiva. Las edades viquianas en el deporte. Fair Play. Revista de Filosofía, Ética y Derecho del Deporte, 3(2), 1-33.

Anzalone, A. (2016). Un latente derecho natural italiano en el siglo XX: Un batallado concepto. Revista Telemática de Filosofía del Derecho, (19), 3-35.

Anzalone, A. y Sánchez Hidalgo A. J. (2016). La areté agonal desde la visión viquiana de la historia. Ingenium. Revista Electrónica de Pensamiento Moderno y Metodología en Historia de la Ideas, (10), 11-28.

Anzalone, A. (2018). Criterios y sentidos de justicia en la dialéctica crociana. Persona y Derecho, (78), 159-188.

Battaglia, F. (1951). Curso de filosofía del derecho. Vol. III. (F. Elías de Tejadas y P. Lucas Verdú, Trads.). Madrid: Instituto Editorial Reus.

${ }^{19}$ En estos mismos términos hemos tenido ocasión de expresarnos anteriormente en Anzalone, 2015, y Anzalone-Sánchez Hidalgo, 2016. 
Battaglia, F. (1960). La formazione spirituale del soggetto e il mondo storico. Bologna: Patron.

Battaglia, F. (1977). La filosofia del diritto in Rosmini. Roma: Giuffré.

Carle, G. (1875). Saggi di filosofia sociale. Torino: Bocea.

Carpintero Benítez, F. (1966). Persona y officium: derechos y competencias. Rivista Internazionale di Filosofia del Diritto, (IV) serie, LXXIII.

Carpintero Benítez, F. (1987). La independencia y autonomía del individuo: los orígenes de la persona jurídica. Anuario de Filosofía del Derecho, (IV), 477-522.

Cerami, P.; Corbino, A.; Metro, A. y Purpura, G. (2001). Ordinamento costituzionale e produzione del diritto in Roma antica. Napoli: Jovene.

Comte, A. (1967). Corso di filosofia positiva. (F. Ferrarotti, Trad.) Torino: Utet.

Croce, B. (1943). Revisione filosofica dei concetti di Libertá e Giustizia. La Critica. Rivista di Letteratura, Storia e Filosofia, (41), 276-284.

Croce, B. (1980). La filosofia di Giambattista Vico. Roma-Bari: Laterza.

Del Vecchio, G. (1905). I presupposti filosofici della nozione del diritto. Bologna: Zanichelli.

Del Vecchio, G. (1945). Evoluzione ed involuzione nel diritto. Roma: Studium.

Del Vecchio, G. (1950). L'unitá dello spirito umano come base della comparazione giuridica. Rivista Internazionale di Filosofia del Diritto.

Fragapane, S. (1896). Il problema delle origini del diritto. Roma: Loescher.

Gentile, G. (1913). La riforma della dialettica hegeliana. Messina: Principato.

Habermas, J. (1992). Teoría de la acción comunicativa, II, Crítica de la razón funcionalista. Madrid: Taurus.

Habermas, J. (1998). Teoría de la acción comunicativa, I, Racionalidad de la acción y racionalización social. Madrid: Taurus.

Jhering, R. (1960). La lotta per il diritto. (R. Marianao, Trad.). Coord. Pietro Piovani. Prefacio de Benedetto Croce. Bari: Laterza. 
Maine, H. S. (1874). L'ancien droit considéré dans ses rapports avec l'histoire de la société primitive et avec les idées modernes. (J.G. Courcelle Seneuil). Paris: Guillaumin.

Maine, H. S. (1883). Dissertations on Early Law and Custom. Londres: John Murray.

Maine, H. S. (1998). Diritto antico. (A. Ferrari, Trad.). Milán: Giuffrè.

Medina Morales, D. (1955). Derecho y Libertad. La teoría de la imputabilidad en Aristóteles. Cuadernos de política criminal, (55), 131-138

Zagrebelsky, G. (2011). El derecho dúctil. Ley, derechos, justiciar. (M. Gascón, Trad.). Madrid: Trotta. 